\title{
Entertainment Game to Support Interaction between Teachers and Students
}

\author{
Marcos Alexandre Rose Silva and Junia Coutinho Anacleto \\ Federal University of São Carlos. Washigton Luis KM 235, São Carlos, São Paulo, Brazil \\ \{marcos_silva, junia\} adc.ufscar.br
}

\begin{abstract}
A narrative game is described here which main goal is to support childrens' free expression and socialization considering their cultural background. This game can be used at school, in which students can develop a story together under the teacher's supervision. The idea is to support teachers to create characters and scenarios according to the students' cultural context, expressed in their common sense knowledge, and consequently enabling them to get engaged on developing the story collaboratively. Also, teacher has the common sense's support to conduct the story according to the facts are being narrated, to stimuli the students' communion. This cultural sensitive RPG-like environment intends to promote a closer contact between teacher and students and among students giving them a more contextualized computer tool to be stimulated to freely express their thoughts, desires and to support them to cooperative work with teachers what is desirable for their intellectual and cognitive development.
\end{abstract}

Keywords: Collaboration, Storyteller, Narrative Game, Context, Common Sense, Education, Educational game.

\section{Introduction}

During childhood, according to Benford et al., [2], it is expected that young children should learn some skills to be able collaborate and realize how important is to live and to communicate with different people, because each person has his own culture, values and socio-cultural reality. These abilities are part of fundamental educational objectives because when children participate actively in their class activities, they cooperate with teacher and other students, building their own knowledge [6]. On the other hand, activities to promote work in group rarely occurs spontaneously [6] so teachers and students need to have activities and tools to leverage and support this style of studying. Thinking of that, an educational computer narrative game to help teachers to work collaboratively with their students through a cultural sensitive storytelling RPG-like environment is presented here.

\section{Narrative Games}

In narrative games, stories are not only understood by people; but they are also experienced in narrative processes that turn people into active characters [9], because 
they participate in the story, telling facts, events, and all the details necessary for the story. Fantasy in narrative games allow people, especially children, to feel safe to express themselves, to talk about situations that occur in their lives because they believe that what happens in fantasy has little or even no consequence in real life. According to Oaklander [9] children do things, behave and move in their fanciful world in the same way in their real world.

The narrative game discussed here has been developed for children from 8 to 12 . According to Piaget [10] in this phase the children are in the stage called Operational Concrete Thought. In this stage child has great interest in games and finds new ways to play and to work collaboratively. They also have facilities to build and to maintain friendships using computers; they usually interact with one another virtually. These are important features for a computer game that allows people to tell stories collaboratively. In this phase children develop academic instruments such as reading, writing and basic math, and they are able to give attention. Thus, children have the capacity to read the story being told, to help to write it, i.e., to participate in building the story and to get attentive to the whole story [10]. During Operational Concrete children are willing to make friends and want to participate and interact with other children's game. Therefore, there are great chances that children can be interested in participating and interacting with the story being told collaboratively.

\subsection{Contexteller}

Contexteller is a narrative game inspired in Role-Playing Game - RPG [11]. In this type of game there are participants and the master, who usually is the most experienced player and his task is to present the story to the group, with characters, their characteristics, scenarios; in short, the necessary descriptions to compose an adventure with puzzles, situations and conflicts that require choices by other participants, who are the players. These players are not just spectators; they contribute actively in the story, through their characters that choose paths and take own decisions, and most of the time not foreseen by the master, contributing to the spontaneous and unexpected development of the story.

Figure 1 shows the interface available for players. This interface allows the players to see their card (I), their dice (II), and the text area (III), which allows the master to read all the messages sent to students and master during the composition of the collaborative story. In area (IV), the card, with another color and size, represents the master of the game, and area (V) shows to other characters' card.

In this narrative game each player chooses a card that represents a character (I) and throughout his/her character the player acts, speaks, thinks and decides the character's attitudes. The card has some RPG elements, such as: Magic, Force and Experience. These elements are considered to be one of the rules existing in RPG. This rule avoids many discussions that could occur during the story.

According to Bittencourt et al., [3] and Claraparede [5], fantasy, challenges and obstacles described by the master and players during the game motivate them to play, because in narrative games, players are curious to get to know the details and are willing to participate in an entire story to achieve the goal proposed by the master. On the order hand, students can feel themselves more interest when they identify the relation between what they are seeing on the content of the story and their reality. In short, they can identify that the content is significant to their life, because it is close to 


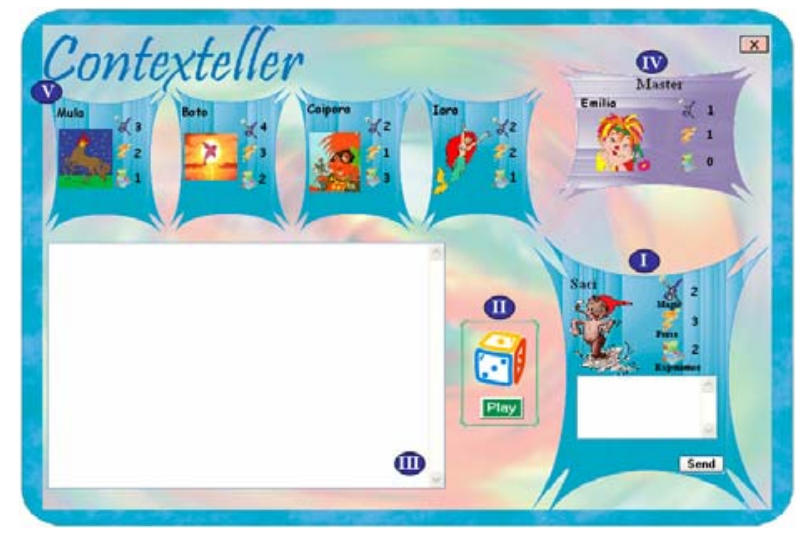

Fig. 2. The interface of the Narrative Game

their reality. Because of this, Contexteller can also help children to notice familiarity with the characters, their characteristics and plot of the story. Therefore, this gives the teacher computer support through contextualized information so that he/she can create and tell stories. This support is provided by common sense that represents cultural aspects of the students' community. Common sense is a set of facts known by most people living in a particular culture, "covering a great part of everyday human experience, knowledge of spatial, physical, social and psychological aspects. In short, common sense is the knowledge shared by most people in a particular culture [1].

The game proposed in this paper, uses the common sense knowledge obtained by the Open Mind Common Sense Project in Brazil (OMCS-Br), developed by the Advanced Interaction Laboratory (LIA) at UFSCar in collaboration with Media Lab from Massachusetts Institute of Technology (MIT) OMCS-Br project has been collected common sense of a general public through a web site. Common sense is then processed and stored in a knowledge base as a semantic network called ConceptNet where the nodes represents concepts and they are connected through arcs that represent relations according to the Marvin Minsky's knowledge model [1]. This base intends to reflect a basic knowledge structure near human cognitive structure.

\section{Setps to Create a Story at Contexteller}

At the Contexteller there are six steps to support teachers to create it.

First, some information about the teacher is stored, such as: name, state, city, among others. Throughout this data it is possible to identify which teacher has created the game. Second, it is defined which students are going to participate, their names, states and school education are some important information. The teacher can identify which students played and how each student told the story. When the teacher registers his students before creating a story, he takes into consideration who are those students in order to define the characters and the plot. After the registers Contexteller gets the students' state and filters the common sense base considering the knowledge collected from the desired profile in order to contextualize the game content for the target group. 
Step three, the teacher need to choose one between two options: Creating a new game or Choosing a existing game. Step four is shown in Figure 2. In this stage the teacher needs to define six characters: one represents her/him and the others represent students. Number 6 is usually used in RPG of cards [7] and according to Díaz-Aguado [6] six is the ideal number to work collaboratively. According to Benford et al.,[2] educational research has found that working in pairs or small groups can have beneficial effects on learning and development, particularly in early years and primary education. 5 players also facilitate the teacher to monitor the whole story that is being told by the players (students). If the number of players has been greater than 5 , the teacher can face difficulties in reading all the messages, in interacting appropriately during the story and in observing the development and behaviour of each character.

There are two common sense cards to support teachers to define the characters' names and characteristics. In the first card (I), the teacher types a characteristic and searches the common sense knowledge base to obtain the characters' names. For instance, if he/she wants to tell a story about forest and know which characters are related to the forest are taking into account, considering the student's knowledge and culture, h/she can type this place on the card. Through the common sense knowledge base the following characters can be seen: Caipora, Chico Bento, Cuca, Saci-Pererê, Iara, Curupira (from the Brazilian folklore), Big Foot, Joãozinho e Maria, Robin Hood, Elves, among others.

In the second card (II), it is possible to obtain the characters' characteristics when the characters' names are written on the card. For example, some characteristics coming up from Caipora's character are: furry, short, happy, red skin, cares; she likes forest and rides a wild pig, etc. The teacher can join this information, which students know about, with the story to define characters and theirs characteristics. Step six, it is necessary to define a subject and a title for the story. In this step the teacher uses common sense through a card from which $\mathrm{h} / \mathrm{she}$ can get specific information of a word typed on the card, such as: CapableOf, DefinedAs, DesireOf, MotivationOf, PartOf. For example, if the teacher is going to tell a story about forest and wants to know what students think about what exists in a forest, h/she can type "forest" on the card and select "PartOf" option, then get some data, such as: characters, characteristics, animals and other things that students believe there are in a forest.

After these steps, the game is created. Students need to identify themselves to see the title and description of the story created for them, and the teacher's name. Then, students choose a character to participate, in a similar interface shown in Figure 2, after they can change the image. This feature allows the student to express himself not only through the story but also through the image. He can choose an image that makes his character sad, joyful, angry and so on.

During the stories the teacher can also get support from common sense knowledge using a card with the same options as that of the common sense card illustrated in step 6. Figure 3 shows a situation where the teacher has described a Caipora's attitude to protect of nature. The teacher, before typing this text, inserted on the card the word "protect" and selected the "DefinedAs" option to know what the students know about it. He/she obtained some information, such as: taking care, nurse, cherish, cradle, attend, lap, etc. This information supports the teacher during story because he/she can see some data that represent students' language and expression and can use them to describe something. For example, the teacher can change the sentence "Caipora is protecting of the forest" by "Caipora is taking care of the forest". 


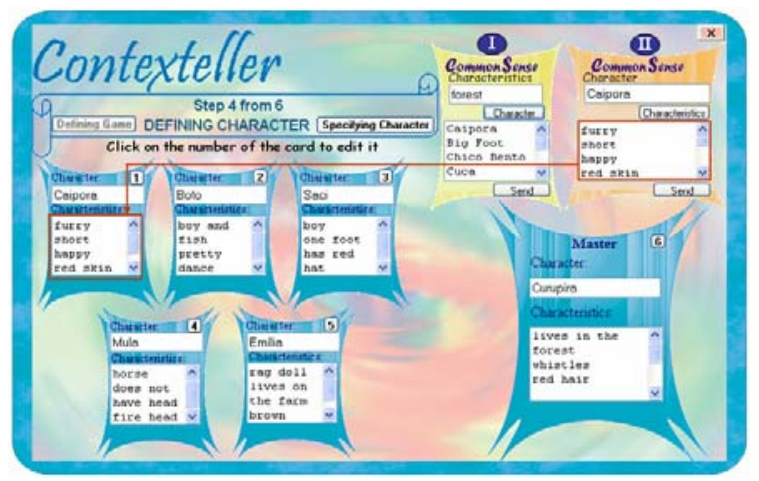

Fig. 2. Defining Characters

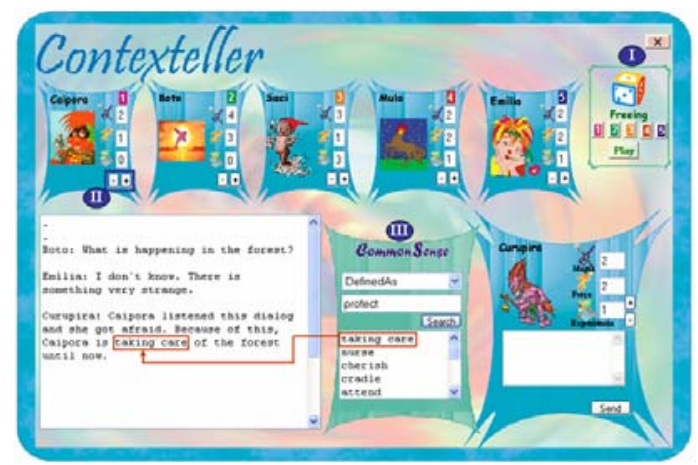

Fig. 3. Teachers' interface

On the teacher's interface there are three different characteristics than those of students', such as: (I) Freeing dice - allows the teacher to through his/her dice and to free the students' dice; (II) Increasing or decreasing the experience' value of each character; and (III) common sense card - which teacher gets information that represent students' cultural knowledge during story.

\section{Conclusions}

This paper has described Contexteller, an environment for online collaborative storytelling where the players jointly develop a story under the master's supervision. The supervision is in order to guarantee that characters and scenarios are culturally contextualized, and also to promote each student's participation and space to express ideas and feeling during the story development. This game can support a teacher to interact with students which have different social and cultural backgrounds, considering these backgrounds before and during the storytelling. Contexteller, a storytelling RPG-like environment is contextualized by Common Sense knowledge in order to 
support teachers on defining the initial context and the content of the game's design considering students' reality and culture. The teacher gets suggestions from the common sense to define the characters, story and its sequence. Through Contexteller, students can also learn to express, to help and to be helped because they need to tell their stories, to help their friends to achieve an objective, and to known that they also need aid to achieve their objectives.

\section{References}

[1] Anacleto, J.C., Lieberman, H., Tsutsumi, M., Neris, V.P.A., Carvalho, A.F.P., Espinosa, J., Zem-Mascarenhas, S.: Can common sense uncover cultural differences in computer applications? In: Bramer, M. (ed.) Artificial intelligence in theory and practice - WCC 2006, vol. 217, pp. 1-10. Springer, Berlin (2006)

[2] Benford, S., Bederson, B.B., Akesson, K., Bayon, V., Druin, A., Hansson, P., Hourcade, J.P., Ingram, R., Neale, H., O’Malley, C., Simsarian, K.T., Stanton, D., Sundblad, Y., Taxén, G.: Designing Storytelling Technologies to Encourage Collaboration Between Young Children. In: Conference on Human Factors in Computing Systems, pp. 556-563 (2000)

[3] Bittencourt, R.J., Giraffa, L.M.M.: A utilização dos Role-Playing Games Digitais no Processo de Ensino-Aprendizagem. Technical Reports Series, Number 031 (September 2003)

[4] Bruckman, A.: Community Support for Constructionist Learning. Computer Supported Cooperative Work: The Journal of Collaborative Computing 7, 47-86 (1998)

[5] Claraparede, E.: Funcional Education, 5th edn. SP: Comp. Nacional, 302 p. (1958)

[6] Diaz-Aguado, M.J.D.: Educação Intercultural e Aprendizagem Cooperativa. Editora Porto, Porto (2003)

[7] Fernandes, V.R.: What is RPG? RPG - Dragon Magazine Brazil, no. 123 (2008)

[8] Järvinen, A., Heliö, S., Mäyrä, F.: Communication and Community in Digital Entertainment Services. Prestudy Research Report (2002)

[9] Oaklander, V.: Windows to Our Children: A Gestalt Therapy Approach to Children and Adolescents, 335 p. Gestalt Journal Press (1988)

[10] Piaget, J.: Judgement and Reasoning in the Child, 268 p. Littlefield Adams, Richmond (1999)

[11] Silva, M.A.R., Anacleto, J.C.: A Narrative Game Culturally Contextualized by Common Sense Modeled as a Semantic Network. In: WSWEd@SBIE - Workshop on Semantic Web and Education, Fortaleza, Brazil (2008) 